\title{
The Impact of Entrepreneurship on Economic and Social Development
}

\author{
Youssef CHAHINE \\ Assistant Professor, Lebanese University \\ Faculty of Economics and Business Administration - Branch 5 \\ E-mail: ychahine@ul.edu.lb
}

Received: May 13, 2020 Accepted: June 2, 2020 Online published: June 18, 2020

doi:10.5296/jpag.v10i2.17206ＵRL: https://doi.org/10.5296/jpag.v10i2.17206

\begin{abstract}
Entrepreneurship is used to denote explorers and innovators in various fields. It has affected by economics, psychology, marketing, sociology, history, strategic management and human sciences. It is also considered as one of the important areas in the economies of developed industrial countries and developing ones. Therefore entrepreneurial projects make an active contribution to expansion of comprehensive economic development in all countries. This paper attempts to provide a theoretical frame work on the concept of entrepreneurship, its importance, characteristics and components. It also deals with the most important obstacles, reforms and the extent of the impact of entrepreneurshipon economic and social development of the country. Many societies face different problems related to pushing economic development forward. Hence, the role of entrepreneurship lay which affect positively and substantially in supporting this progress.
\end{abstract}

Keywords: entrepreneurship, creativity, innovation, supply, demand, organizations, pro-activeness, competiveness, development, society, economics

\section{Introduction}

Entrepreneurship is an old, renewed, recent phenomenon which is used to denote creators and innovators in various fields. The roots of entrepreneurship refers to oligopoly theory where the entrepreneur was just able to deal which calculation of quantities prices that would produced and made an appropriate decision about it until the economist Karl Marx came and mentioned the entrepreneur as an agent of economic and technical change and an effective influencer in society (Blaug, 2000).

Entrepreneurship has been affected by economics, psychology, marketing, sociology, history, strategic management and human sciences which led to interpretations and multiple theories 
and it is not wrong to say that there is no consensus on a specific entrepreneurship (Hoselitz, 1952).

Entrepreneurship is considered as one of the important areas in the economies of the developed industrial countries and developing ones. Therefore entrepreneurial projects make an active contribution to expansion of comprehensive economic development in all countries (Seth, S. 2019).

Arthur Cole considered as the first one who established entrepreneurial history research center at Harvard University in 1948, points out that entrepreneurship is achieved through the creation of business organization and work to develop industries and invest in them to develop the national economy (Hughes, 1983).

At the individual level an entrepreneurial project ensures personal income, self-realization, moreover contributes to developing new jobs, reducing unemployment levels in society. In addition to new goods and products newly emerged services lead to the creation of new markets and contribute to reducing the gaps in the economies of all countries.

More over the most important motive for economic growth is the availability of the entrepreneurs, creative people. Therefore the most important thing to do to animate a society not only the availability of one hundreddistinguished economist or politician but one hundred entrepreneurs holding creative ideas (Nelson, 1977). So we should take into consideration that entrepreneurship is an effective strategic choice to face the potential changes in the external environment; this mainly depends on the entrepreneurial orientation adapted by the entrepreneurs.

After reviewing previous studies (Jennings, 2004), most of them dealt with entrepreneurship individually, or with the impact of creativity on entrepreneurial organizations and the impact of quality on entrepreneurship as well as skills associated with entrepreneurial activities (Irigoyen, 2004).

This paper looked at the impact of entrepreneurship on social and economic life. Here lay the importance in addressing a problem posing it to academics who are interested in entrepreneurship, as well as for owners of small and medium enterprises to benefit and learn more how to face what mayintercept them.

How does entrepreneurship affect economic and social development? What is the concept of entrepreneurship? What are the most important obstacles? How to overcome? What is the impact of entrepreneurship on the economy and social development?

Many societies face different problems related to promote economic development forward. Hence the role of entrepreneurship lay which affect positively and substantially in supporting that. This paper is divided into five sections: the first is the introduction; the second is about entrepreneurship, concepts, importance, characteristics and components, the third presents obstacles to entrepreneurship, while the fourth section introduces the developmental effects of entrepreneurship and small businesses in the national economy, and the fifth section included the conclusion. 


\section{Entrepreneurship}

\subsection{The Historical Development of Entrepreneurship Concept}

The concept of entrepreneurship is an old one. It was first used in the French language at the beginning of the sixteenth century. Then the term "entrepreneurship" was popularized in English literature, which included the meaning of risk and bearing difficulties that accompanied to military explorations campaigns. (Murphy, 1986) The concept of entrepreneurship entered into economic activities in the early eighteenth century by Richard Cantillon who considered the trader who buys goods at specific price to sell it in the future at a price that does not know beforehand, is an entrepreneur (De Vecchi, 1995).

In the nineteenth century, the entrepreneur was separated from the owner of the capital; the inventors didn't have the money to finance their invention. Rather, they obtained money from various sources but they created a new good. Therefore they are entrepreneurs not owners of funds. Hence Joseph Schumpeter's opinions came in 1934 who considered the entrepreneur as the cornerstone of economic development, which gave a new dimension to the concept of the entrepreneurship.

\subsection{Entrepreneurship Concept}

The entrepreneurial concept refers to Joseph Schumpeter, an Austrian political economist, who popularized the term "creative destruction" in economics, defined the entrepreneur as 'The one who has the ability and the will to convert a new idea or a new invention into a successful innovation' (Backhaus, 2006). He added that 'Entrepreneurship uses what is called creative destruction storm in order to replace, in part or in full, a modest product with/by a highest quality product in the markets and in the industrial world'.Thus, creative destruction is largely responsible for economic growth in the long term (Sobel, 2000).

Frank Hyneman Knight and Peter Ferdinand Drucker considered that entrepreneurship is centered on taking the risk whereas the entrepreneur's behaviors reflects the type of ability he has to develop his career and high financial position, by applying his idea and putting it into practice by giving it more time and effort and capital in as unsecured risk (Astebro, 2014).

Some entrepreneurs point out that entrepreneurship refers to the identification of opportunities and to the use of resources and capabilities to implement innovative ideas for new adventures, while others assert that it is a strategic choice that nominates the organization's business model to meet change in customer needs helps take a competitive position in the market (Sobel, 2000).

Entrepreneurship is trying to develop the internal entrepreneurial spirit, philosophy and structure that will produce a greater number of mediating innovations.

\subsection{The Importance, Characteristics and Components of Entrepreneurship}

\subsubsection{The Importance of Entrepreneurship}

In recent years interest in entrepreneurship has increased especially with the pace of change on business environment and increased competition among organizations. This topic has 
become increasingly important as one of the options that organizations resort to adopt and align with competition and change requirements, and thus any emerging project is seen as an effective way to create demand and new markets, and the employing of a number of manpower and their contribution which can be measured in terms of the impact it has on important areas in the economic system such as: job creation, creativity and its importance for big business (Shane \& Venkataraman, 2000).

Entrepreneurship is considered a very important issue in societies for many reasons below:

-Entrepreneurship generates creativity and change, especially technical change, and thus works to achieve economic growth (Shane \& Venkataraman, 2000).

-Entrepreneurship is the process by which supply and demand are balanced (Shane \& Venkataraman, 2000).

-Entrepreneurship is the process by which knowledge is transformed into new products and services.

-Entrepreneurship is an important reputation for business as a strategy for growth and competitive advantage (Tan \& Tan, 2004).

-Entrepreneurship has a positive impact on the economy and society, as it helps to stabilize it.Joseph Schumpeter was the first who signified it in his book "Theory of Economic development" (Barringer, 2015).

\subsubsection{The Characteristics of Entrepreneurship}

The subject of characteristics is an independent subject, but rather a presentation of personal formation of individuals in general. Entrepreneurial characteristics are personal and feature abilities that and entrepreneur possesses, which he needs to successfully manage his organization in defining his methods of behavior in various situations he may face, or the role he performs depending on the type of tasks required to be implemented.

Here are some characteristics of entrepreneurship which can be considered the key to success in the new project, as follows:

-Ability to better identify potential project opportunities than others, as it focuses on opportunity not on problems, and an attempt to take advantage of failure. Entrepreneurs are goal-oriented and have a powerful influence on the emerging culture of the organization. They are able to visualize where the organization is going, and therefore they are able to provide a strong sense of strategic orientation.

- Feeling of urgent need to make it practical oriented, they have a high need for achievement, which motivate them to put their ideas into practice that they tend to be in the internal position of the censorship leading them to believe that they can determine their fate through their own behavior. They also have a much greater ability to tolerate ambiguity and tension than to create many organizations.

-Detailed knowledge of the keys to industry success that makes their work their lives. -Get external help to support their skills, knowledge and abilities, as time passes, it creates a network of people with basic skills and knowledge who can be called businessmen to obtain support. 


\subsubsection{The Components of Entrepreneurship}

Researchers identified several components, some of who agree with others on a set of components and some of them differ, and some of them who add or exclude some components, but the most important components are as follows (Masters \& Meier, 1988):

\subsubsection{Risk-taking}

Taking risk is the probability of getting reward or achieves returns in the event of a successful business plan, and it indicates organizations preference to seize new opportunities even if they do not know if the new project will be successful and to act boldly without knowing the results.

Entrepreneurial successful organization usually takes risk even if that means leaving methods or products they were previously working on. For high financial return, organizations sometimes run the riskof borrowing large sums and committing to large amounts of organizational resources and introducing new products to new markets and investing in undiscovered technology (Masters, 1988).

\subsubsection{Pro-Activeness}

It resembles the initiative in actions, then waiting for the competitors to respond (Covin, 1991).Organizations are able to reinforce proactive measures if they have an organizational culture that motivates managers to take entrepreneurial behavior. Therefore, they are able to create new business units that are profitable more quickly than others, and this allows them to take advantage of profitable opportunities for diversification. It has been mentioned that the organization is proactive in providing new goods or services to the market as it was the first start of markets in introducing a new product (Hisrich, 1990).

\subsubsection{Creativity}

It is the process of finding new things that are central to entrepreneurial process (Barringer, 2015). It has many benefits that are reflected in several services, markets and businesses, and it can be pointed out as follows:

-Generating, changing and producing advanced commercial products, as well as services and market operation.

-Increasing productivity and profitability, as well as increasing jobs with high wages and economic growth.

- Accelerating the transition from raw growth to fair and sustainable growth through transforming and improving organizations and developing models (Hill, 2014).

\subsubsection{Competitive Intensity}

The intensity of the competitiveness is a group of efforts of organization that work better than their competitors in the industry, the often venture against competitors, reduce prices and scarifies profits to obtain market share, or they are largely spent to obtain manufacturing capacity and as a way to develop and grow the organization. The competitive adventure may take the organization very risky in raising the results of other entrepreneurial activities such 
as creativity and pro-activeness. The intensity of the competition differs from creativity and pro-activeness in that it looks directly to competitors while the other two dimensions focus on market opportunities in its competitive environment.

\section{Obstacles to Entrepreneurship}

Entrepreneurship has played a vital role in sustainable development and contributed to the participation of all categories of society in the economic movement, especially the youth, but it has faced several challenges which contributed to the success of them and ceased a number of others.

\subsection{Obstacles Facing Entrepreneurs and Entrepreneurial Projects}

There are many obstacles that limit the capabilities of entrepreneurs as a result of sticking to the routine and ensuring bureaucratic systems and the establishment on centralization and other obstacles that limit innovation and creativity which causes frustration for entrepreneurs.

\subsubsection{Administrative Obstacles}

Administrative obstacles are the most important obstacles facing entrepreneurs, in terms of their contribution of squandering efforts to support small and medium enterprises as a result of the lack of ability to plan, to formulate and implement strategies that adapt to the economical environment (El Alaoui et al., 2016). Administrative obstacles that stand in the way of innovation and creativity can be listed as follows:

-Poor marketing experience in small and medium enterprises, poor product quality, and problems in dealing with clients and collecting dues from them.

-Poor organizational ambiance and precocious criticism of new ideas without waiting for results.

-Poor economic conditions, which include low wages and salaries and insufficient incentives, which drives experienced workers to drop out, or search for supplementary job to increase income.

-Inability to deal with the various challenges racing small enterprises in different stages of development, such as product development, increasing investment in stock and increasing production capacity.

\subsubsection{Economic and Social Obstacles}

There are a host of obstacles facing entrepreneurs.

-Poor financing and difficulty in obtaining it: This means that there are difficulties facing entrepreneurs in obtaining various loans to finance their projects as a result of the requirements and various routine procedures. Below are signs of underfunding:

- Banks and financial institutions overstating the guarantees required to financing small projects.

- The relatively small amount of loans to small projects by banking institutions. 
- The complexity of the procedures required to obtain loans.

- The trend of commercial banks to finance large projects and law financing for small projects.

- Bank institutions interfering and imposing trusteeship on projects.

- High interest rates on the loans.

- Lack of awareness of the investor in small projects with the opportunity of foreign financing.

-Reduced demand for small enterprise products to economic recession: The economic recession leads to a decrease in demand for product in general, with the limited purchasing power of individuals, and it results as asurplus in production capacity, which limits the ability of owners of small and medium enterprises to survive, and may lead to bankruptcy.

-Lack of information: The most important problems facing entrepreneurs is the lack of information that limits the role of entrepreneurs. You may find a lack of information on the resource and commodity markets and production requirements, as well as a lack of information on government regulations and decisions such as project registration systems, incentives, taxes, social insurance and labor laws, in addition to duplicating the same activity in the same area due to the lack of a map showing a small projects.

-Poor efficiency of the human resources operating in small and medium enterprises projects: There are many small enterprises that lack regular accounting financial records because there are now qualified accountants, and that the projects financial liability is not separated from private property of the project owners, and a lack of human cadres that plan, organize and control due to poor educational qualifications, low training level and the unwillingness of some workers in small enterprises to develop their capabilities.

\subsection{Modernization Trends to Support Entrepreneurship}

There are many initiatives that provide trends to modernize entrepreneurship which include encouraging support for small and medium-sized enterprises especiallyentrepreneurial ventures some of these trends that seek to support entrepreneurship include:

a- Integrating entrepreneurship into the educational system, by spreading the culture of the entrepreneurship in educational stages, especially in higher education to establish creativity, risk skills and to develop educational programs at the level of higher education, as well as in the early educational stages like primary schools with a focus on preparing activities that encourage students to actively participate besides personal initiatives as well as in the intermediate and secondary levels to provide entrepreneurship education with a case study based on role model and incorporating e-content into the curriculum and to develop training programs to enhance entrepreneurial skills for university graduates. 
b- Simplifying entry and exit procedures for markets, guarantees and labor laws:if we scan different experiences in all countries, we notice (realize) the simplification of procedures and reducing the cost of establishing enterprises in terms of enacting clear bankruptcy laws that guarantee the investor's right in the event of liquidation of the enterprise, or on his desire to sell his share. Experiences have also shown that countries adopting a "one-stop shop" policy to simplify procedures for initiating activity, and use different electronic registration system, provide a stable business environment without frequent or sudden changes to law and legislation in which corruption aspects are reduced.

c- Reducingtax burdens according to the nature of establishments: the tax system must not be biased against small enterprises, and does not treat them as the treatment of large enterprises, the tax system must also take into account the size, age, degree of risk, growth prospects and nature of markets for emerging enterprises. There are many experiences in which tax burdens are eased across high growth enterprises to encourage certain forms of financing by contributing to the capital of enterprises operating in the field of modern technologies based on innovative ideas for the purpose of encouraging innovation, development and technology.

d- Improving market access: one of the best ways to improve SMEs market access is to reduce barriers for foreign trade, investment and to reform the regulatory framework for these enterprises, reduce transaction costs, and help these enterprises adopt international standards and specifications.

e- Providing infrastructure and information: for a successful entrepreneurial culture, an adequate infrastructure is required, such as transportation, electricity, road, post and support services and accurate and up-to-date information is needed to support the entrepreneurial environment.

f- Submitting support programs for small and medium enterprises regarding financing: It is necessary to increase the awareness of SMEs about the available financing windows and financing products provided by banks and other financial institutions, and provide information about the available support programs in the area of preparing investments plans, financial accounts, feasibility study, loan application and strengthening the incentives for back financing for entrepreneurial facilities by using non-compulsory means such as reducing the legal reserve ratio for the banks that allocate a certain percentage of their loan portfolio to the benefit of entrepreneurial facilities, and support programs can be provided in the form of non-financing services for entrepreneurial facilities. Support programs can also be provided in the form of non-financing services for financial institutions as training in the field of strategic planning, improving its competitiveness or other advisory services.

g- Developing the capacity of financial institutions in terms of landing to start-ups, by urging financial institutions to adopt modern landing models and sophisticated to classify borrowers and evaluate loan applications, and avoiding bias in those institutions against small and medium enterprises in favor of large enterprises. 
Here businessmen associations and chambers of commerce must enhance administrative skills, and provide business development services for the benefit of establishments and assisting them in addressing the obstacles that hinder their access to finance, such as guarantees and credit information.

h- Establishing specialized institutions for credit information, because relying on these institutions contributes to increasing bank lending to small and medium-sized enterprises, where it provides information on loan operations and credit history. In some countries there are institutions that specialize in assessing the credit worthiness of SMEs.

\section{The Developmental Effects of Entrepreneurship in the National Economy}

Entrepreneurship plays an important role in the national economy, because it is able to contribute effectively to the re-calibration and restructuring of production, which represent the basic element for comprehensive development, as it employs many manpower that contribute to limiting the aggravation of unemployment, thus achieving the regional balance for development that the state seeks to achieve in its various plans for comprehensive development. Therefore, entrepreneurs are more important to the economies of countries because they achieve comprehensive development and have many economic and social impacts as they play a major role in the national economy and local development.

\subsection{The Role of Entrepreneurship in Economic Development}

Entrepreneurs play an axial role in supporting the economies of developed and developing countries alike. On the economic front, there is a strong relationship between entrepreneurs and increasing the per ca pita share of GDP.

The economic impact of entrepreneurship can be summarized as follows:

a- Increasing in average per ca pita income and change in business and community structure:

Entrepreneurship increases the average per ca pita income, and changes in business and community structure. This change is accompanied by growth and increase in outputs, and this allows the formation of wealth for individuals by increasing the number of participants in development gains, thus achieving equity in the distribution of development gains.

b- Increasing in supply and demand: Procurement new capital expands the growth side and the utilization of new outputs and potentials leads to growth on the demand side as it increases both supply and demand sides.

c- Renewal, innovation and ability to bridge the gap between knowledge and market need: Development depends on innovation not only to developing a new product or service for the markets but also by concerning to simultaneous investment in procuring new project. Hence, entrepreneurs are more sources of innovation and creativity and risk than large public firms because- good people who work to invent new ideas that affect the profit- find incentives that drive them directly to work.

d- Directing activities to the targeted development areas:Government can encourage the trend 
towards entrepreneurship in certain businesses such as technological works or encourage the orientation toward specific regions through some incentives for entrepreneurs to establish their projects in those specialties or areas.

e- Developing exports and maintaining the permanence of competition: Organizations can contribute in developing exports whether through direct and indirect production and this is what happens in some countries where loans to entrepreneurs play a fundamental role in driving economic activity in terms of providing job opportunities and basic services to the local market. It also contributes in developing exports to the developed countries by creating intermediate goods needed by large projects abroad and at home, which stimulates the support of international firms for them. International firms are also interested in providing incentives to attract capital for these projects, creating an incubating environment for them in terms of issuing their own legislation and facilitating matters of financing, management and marketing of their products.

f- Popularity of franchises: The importance of entrepreneurs in the national economy in different countries increases with the popularity of franchise. In fact the franchise was the savior of many independent wholesalers and retailers with increased competition from multi-branch organizations, especially in the world of economic openness. This underscores the importance of entrepreneurs in supporting the national economy. Franchises export abroad a way of living, culture and invest in idea, product, commodity and service. It must be viewed from the perspective of wealth from the idea to the brand.

g- Working to develop the economy: Small entrepreneurial projects are often the bases for developing the economy and they are the nucleus that supplies the national economy later with the mega projects, whether in developing them or with the ideas they provide. Today's small projects are tomorrow's big projects.

\subsection{The Role and Importance of Entrepreneurship in Society}

In general the entrepreneurial process is very important in society for several reasons:

-Entrepreneurship generates creativity and change, especially technical change, and thus works to achieve economic growth.

-Entrepreneurship is the process by which supply and demand are balanced.

-Entrepreneurship is the process by which knowledge is converted into products and services.

-Entrepreneurship has become an important task, and there is a need to understand its role in developing human and intellectual capital.

Ricky W. Griffin believes that small entrepreneurship is important in emerging economies, and its importance and contribution can be measured in terms of its impact in important and major areas of the economic system, such as job creation, creativity and its importance for large business in terms of: service provision, retail, wholesale, construction work, transportation, insurance, finance and manufacturing. The global entrepreneurship report indicates that there is a direct relationship between increasing entrepreneurial activities and increasing economic growth in the countries covered by the report, which is confirmed by the 
increased interest in entrepreneurship globally, and its inclusion in curricula as well as some activities and events that the entrepreneur stimulates in society and in the labor market (Griffin, 2013).

Entrepreneurial organizations these days do not grow or develop through the increase in the number of workers in them, to the extent that their growth and development is affected by their continuous search for their resources locally and internationally, in a manner that reduces the cost of goods or services that these organizations produces.

Entrepreneurs contribute to enhancing the social dimension, as they are the only ones capable of transferring educational outcomes from those looking for work to creating job opportunities, in addition to the social importance - that entrepreneurs have gained through their contribution to raising the rates of social development - is no less important than the role these projects play to achieve economic development, where we find that these projects play a clear role in addressing many social problem such as unemployment, neutralization, idleness and the multiple social risks that follow. Thus, it protects society from social, security and psychological negatives resulting from the spread of this social phenomenon.

In the same context entrepreneurs are working to reintegrate the laid off from their jobs, due to bankruptcy of some projects, or by reducing the size of employment in them, as a result of restructuring or privatization, which supports the possibility of indemnity for some lost activities.

The social impact of entrepreneurship can be summarized as follows:

a- Social development justice and wealth distribution:Most economic and social development plans usually aim to redistribute wealth, and fairness in wealth distribution and distributing economic and social development gains to different crowded cities, which are usually considered home to large projects. Hence, entrepreneurs and in their various projects, whether small or medium and through their geographical spread and large scale are capable of creating efficient and comprehensive regional developments assisted by exploitation of available local resources and capabilities, and their lack of need for infrastructure, which makes it contribute to achieving social justice among various cities in the world.

b- Absorbing unemployment and providing new job opportunities:Entrepreneurs in small and medium-sized organization play an important role in the modern economy in all countries due to their flexibility and creativity, where they play a major role in providing job opportunities and absorbing unemployment, as the cost of job opportunities is less than the average cost of work in large organizations.

c- Activating the role of women: empowering and supporting women economically and creating an environmental system that contributes to their success. Besides launching some initiatives to enhance women's participation and address some of the issues facing them. Entrepreneurship helps encourage women to start entrepreneurial activities, thereby making an active contribution to building the national economy (Torun, 2016). 
d- Reducing population migration:One of the mainstays in stabilizing the population and non-migration from the countryside's to the cities is the presence of entrepreneurs and small organizations in the national economy. Therefore, there must be developmental programs that help in reducing poverty and unemployment, and working to build a middle class in the country sides instead of migrating to cities where pollution and pressure on infrastructure services, and that is only by caring for entrepreneurs and small organizations, and cooperation with various international firms and organizations. Moreover, small and medium enterprises play a strategic role in achieving the principles of human development, by expanding alternatives and options for people, whether from a variety of work or a variety of goods and services. Helping small and medium companies contribute to creating suitable opportunities for the youth.

\section{Conclusion}

An entrepreneur is commonly seen and perceived as an innovator. The skills required for successful entrepreneurship are innovation and ability to be creative to generate new ideas for a business venture. Entrepreneurship is considered as one of the important areas in the economies of the developed industrial countries and developing ones. Therefore entrepreneurial projects make an active contribution to expansion of comprehensive economic development in all countries. Entrepreneurship has played a vital role in sustainable development and contributed to the participation of all categories of society in the economic movement, especially the youth, but it has faced several challenges which contributed to the success of them and ceased a number of others. Entrepreneurship plays an important role in the national economy, because it is able to contribute effectively to the re-calibration and restructuring of production, which represent the basic element for comprehensive development.

According to the above, the social and economic impact of entrepreneurship can be summarized as follows:

\begin{tabular}{|l|l|}
\hline Economical impact & Social Impact \\
\hline Increase average of individual income & Creating jobs \\
\hline Increase in outputs & Produce creativity \\
\hline Increase in macro demand & Environmental development \\
\hline Increase in supply & Increase in knowledge \\
\hline Developmental and geographical balance & Increase social development rates \\
\hline Increase in investment & Treatment of unemployment and neutralization \\
\hline Export development & Reducing poverty \\
\hline The vogue of franchises & $\begin{array}{l}\text { Activating the role of woman in community and } \\
\text { society }\end{array}$ \\
\hline Developing and diversifying the economy & Achieving justice and distribution of wealth \\
\hline Exploitation of local resources & Reducing migration \\
\hline
\end{tabular}




\section{References}

Astebro, T., Herz, H., Nanda, R., \& Weber, R. A. (2014). Seeking the roots of entrepreneurship: Insights from behavioral economics. Journal of Economic Perspectives, 28(3), 49-70. https://doi.org/10.1257/jep.28.3.49

Backhaus, J. G. (2006). Joseph Alois Schumpeter: entrepreneurship, style and vision (Vol. 1). Springer Science \& Business Media.

Barney, J. B., \& Griffin, R. W. (1992). The management of organizations: Strategy, structure, behavior. Houghton Mifflin College Div.

Barringer, B. R. (2015). Entrepreneurship: Successfully launching new ventures. Pearson Education India.

Blaug, M. (2000). Entrepreneurship before and after Schumpeter. Entrepreneurship: The social science view, 76-88.

Covin, J. G., \&Slevin, D. P. (1991). A conceptual model of entrepreneurship as firm behavior. $\begin{array}{lllll}\text { Entrepreneurship theory and } & \text { 7-26. }\end{array}$ https://doi.org/10.1177/104225879101600102

De Vecchi, N. (1995). Entrepreneurs, institutions and economic change. Books.

El Alaoui, A., Shopovski, J., Kvirkvaia, M., Alam, N., \& Ofili, O. U. (2016). Obstacles to Entrepreneurship in Albania, Georgia, Morocco, Nigeria, and Pakistan. European Scientific Journal, 12(34), 394-398. https://doi.org/10.19044/esj.2016.v12n34p394

Griffin, R. W. (2013). Fundamentals of management. Cengage Learning.

Hill, C. W., Jones, G. R., \& Schilling, M. A. (2014). Strategic management: theory: an integrated approach. Cengage Learning.

Hisrich, R. D. (1990). Entrepreneurship/intrapreneurship. American psychologist, 45(2), 209. https://doi.org/10.1037/0003-066X.45.2.209

Hoselitz, B. F. (1952). Entrepreneurship and economic growth. The American Journal of Economics and Sociology, 12(1), 97-110. https://doi.org/10.1111/j.1536-7150.1952.tb00480.x

Hughes, J. R. (1983). Arthur Cole and entrepreneurial history. Business and economic history, 133-144. https://doi.org/10.2307/envrev/7.2.133

Irigoyen, C. (2004). Where do entrepreneurs come from?.

Jennings, D. F., \& Hindle, K. (2004, August). Corporate entrepreneurship and equifinality: an empirical analysis of strategy-structure-performance. In Academy of Management Proceedings (Vol. 2004, No. 1, pp. H1-H6). Briarcliff Manor, NY 10510: Academy of Management. https://doi.org/10.5465/ambpp.2004.13862972

Masters, R., \& Meier, R. (1988). Sex differences and risk-taking propensity of entrepreneurs. Journal of small business management, 26(1), 31. 


\section{Macrothink}

Journal of Public Administration and Governance ISSN 2161-7104 2020, Vol. 10, No. 2

Murphy, A. E., \& Murphy, F. E. E. A. E. (1986). Richard Cantillon: entrepreneur and economist. Oxford university press.

Nelson, R. E. (1977). Entrepreneurship education in developing countries. Asian Survey, 17(9), 880-885. https://doi.org/10.2307/2643595

Seth, S. (2019). Why entrepreneurship is important to the economy. Investopedia Articles.

Shane, S., \&Venkataraman, S. (2000). The promise of entrepreneurship as a field of research. Academy of management review, 25(1), 217-226. https://doi.org/10.5465/amr.2000.2791611

Sobel, R. (2000). The entrepreneurs: Explorations within the American business tradition. Beard Books.

Tan, W. L., \& Tan, T. M. (2004). The impact of corporate governance on value creation in entrepreneurial firms.

Torun, E. (2016). Education Level of Women Entrepreneurs and the Obstacles they Face: The Case of Kocaeli. The Anthropologist, 24(2), 509-518. https://doi.org/10.1080/09720073.2016.11892044

\section{Copyright Disclaimer}

Copyright for this article is retained by the author(s), with first publication rights granted to the journal.

This is an open-access article distributed under the terms and conditions of the Creative Commons Attribution license (http://creativecommons.org/licenses/by/4.0/). 